Supplement of Hydrol. Earth Syst. Sci., 20, 39-54, 2016

http://www.hydrol-earth-syst-sci.net/20/39/2016/

doi:10.5194/hess-20-39-2016-supplement

(C) Author(s) 2016. CC Attribution 3.0 License.

(c) (1)

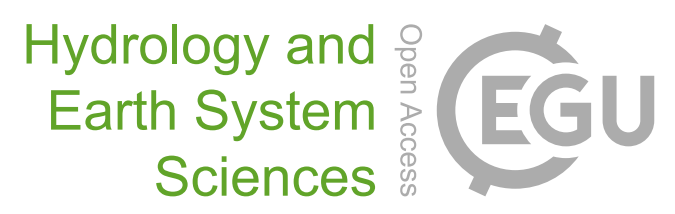

Supplement of

\title{
Accelerated gravity testing of aquitard core permeability and implications at formation and regional scale
}

W. A. Timms et al.

Correspondence to: W. A. Timms (w.timms@unsw.edu.au)

The copyright of individual parts of the supplement might differ from the CC-BY 3.0 licence. 
The centrifuge in this study (Fig. S1) is a Broadbent GT-18 Modular Geotechnical Centrifuge (a $22 \mathrm{~kW}$ motor drives a variable speed of 10 to $875 R P M$ ) on which two modules can be fitted: either a centrifuge permeameter GMP GT2/0.65F or a geotechnical beam GMB GT6/0.75F (Broadbent, 2011; Timms et al., 2014). The geotechnical beam module is not discussed further in this study. The centrifuge permeameter (CP) module was designed specifically for groundwater research while the base centrifuge and geotechnical beam module are standard. Table 1 describes the specifications and performance details of the centrifuge system designed by Broadbent and the University of New South Wales, Australia. By contrast, smaller diameter centrifuge permeameter modules were designed for a similar centrifuge at the University of Texas are of smaller diameter (McCartney, 2007).

The centrifuge permeameter (CP) system, which includes advanced influent and effluent systems (Supplement S3), enables relatively rapid and repeatable testing of large drill core ('H' or 'C' core diameter 65 to $101 \mathrm{~mm}$, length 30-200 mm)_with realistic stress conditions. A low flow rotary union with a capacity of 0.1 to $100 \mathrm{~mL}$ minute ${ }^{-1}$ connects the influent lines A and B to permeameters 1 and 2 without cross flow between the two influent lines. Unlike UFA centrifuge systems this flow union is not sealed, so the maximum head of fluid within this centrifuge is the radial distance from the rotary union to the top of the sample (a distance of approximately $550 \mathrm{~mm}$ assuming a $100 \mathrm{~mm}$ length of core).

Each CP has a maximum sample capacity weight of $4.7 \mathrm{~kg}$. In this system, at maximum centrifuge RPM, a centrifugal force of $556 \mathrm{~g}$ applies at the base of the core samples at a radius of $0.65 \mathrm{~m}$ from the centre of rotation. The relatively large CP module allows on-board instrumentation and real-time monitoring of a range of parameters within a pair of permeameter bodies balanced at either end of the rotating beam. Since a maximum $g$-level of 471 applies at the centre of the sample weight, the rating of this module is $2.2 \mathrm{~g}$-ton $(471 \times 4.7 / 1000)$, and is a relatively small geotechnical centrifuge module (Zornberg and McCartney, 2010). The total weight of each of the pair of centrifuge permeameters when empty is $12.4 \mathrm{~kg}$ plus an allowance of $1.0 \mathrm{~kg}$ of effluent in the reservoir. Routine testing of low permeability porous media is possible with a large cross-sectional flow area (100 mm diameter), influent pumps with variable speeds capable of low flow, and effluent detection systems. Weighting discs to simulate stresses on cores of up to 2 MPa (at maximum RPM) have also been developed for consolidated samples requiring testing at higher stress. 
$1 \quad$ S2 Fluid pressure, head and gradient in centrifuge permeameters

2 Concepts for fluid flow at accelerated gravity are illustrated in Fig. S2 and Fig. S3. The

3 hydrostatic fluid pressure (Eq. 1), measured at a radial position within the core sample, 4 increases with distance from the axis of rotation, continues into a pressured reservoir 5 boundary or decreasing to zero at a free drainage boundary. By contrast, the centrifuge 6 inertial (elevation) head decreases with increasing distance from the axis of rotation, as 7 shown by Nimmo and Mello (1991) and McCartney (2007). It follows that the direction of 8 fluid flow is outwards, in the opposite direction to the axis of rotation.

9 Calculated pore fluid pressure and total stress are shown in Fig. S2 for a $50 \mathrm{~mm}$ length core at $40 \mathrm{~g}$ for the Broadbent CP module, based on Eq. (1) and Eq. (2), in $0.005 \mathrm{~m}$ increments of radius. The effective stress, the difference between the total stress and pore fluid pressures, is evidently highest towards the base of the core, before the effects of a free drainage base (zero pressure) occur within the core. At $40 \mathrm{~g}$, the total stress at the base of the core is $40 \mathrm{kPa}$, or 34 $\mathrm{kPa}$ plus $6 \mathrm{kPa}$ of stress at the top of the core assuming a fluid head of $20 \mathrm{~mm}$ ponded on the top of a $50 \mathrm{~mm}$ length of core. At $80 \mathrm{~g}$, the total stress at the base of the core is $74 \mathrm{kPa}$. This is significantly less than the maximum in situ stress for core samples listed in Table 3, calculated using Eq. (3), as intended during test design (Section 4.2). Centrifuge $K$ values reported in this study could therefore be biased on the high side if total stress at the base of the core under steady state conditions were the only consideration.

The gradients that drive flow are depicted in Fig. S3, with the most significant driving force being due to centrifugal acceleration. The numerical analysis of fluid pressures that develop during flow and transition to new $g$-levels is beyond the scope of the current study.

Figure S3 shows the water head gradient of 0.4 (at $1 \mathrm{~g}$ ) compared with the centrifuge "elevation head" gradient or centrifuge inertial force that drives fluid flow within the centrifuge for both the Broadbent CP module and the UFA system at $40 \mathrm{~g}$. Thus, the Broadbent CP module achieves a more constant $g$-level over the length of a $50 \mathrm{~mm}$ core than is possible with the smaller UFA system. The centrifuge elevation gradient driving flow is significantly greater than the water head gradient that would occur at $1 \mathrm{~g}$, and is more uniform in the Broadbent CP module ( $37 g$ to $40 g$ ) compared with the UFA system ( $23 g$ to $40 g$ ), being a variation of $7 \%$ and $41 \%$ respectively. 
1 Non-linearity in pore pressure distribution is considered to be insignificant where the ratio of

2 radius and sample size $(r / L)$ is large (Nakajima and Stadler, 2006). In their study, the $r / L$ ratio was 8 (2.0/0.25). By this criteria it is noted that for the examples given here, the $r / L$ ratio of 130 (0.65/0.005) in the Broadbent CP module is more favourable than for the UFA setup with the $r / L$ ratio of $22(0.11 / 0.005)$. Timms et al. (2003) noted that accurate scaling of physical factors (eg length, time) in the UFA centrifuge was limited by differing acceleration and stress experienced at the top and base of the core. A larger radius centrifuge operated at lower speeds minimises stress gradients within the core, thus minimising the possibility of variable stresses affecting the structure of the core sample.

S3 Centrifuge permeameter flow systems and instrumentation

In addition to the Broadbent CP module, some unique systems were developed as part of this study. Influent was fed from a pair of burettes located next to the centrifuge via a pair of custom designed low voltage peristaltic pumps mounted either on the centrifuge beam, or outside the centrifuge and through the low flow rotary union described in Supplement S4. The peristaltic pumps can be operated either as zero/maximum flow to a set level, or at a variable flow rate of $0.001-150 \mathrm{~mL}$ hour ${ }^{-1}$. Manual burette measurements to a resolution of $0.1 \mathrm{~mL}$ were used to verify the pump rates.

A personal computer (PC) with LABVIEW software was used for data logging and control of the influent pumping system, which was originally connected via an Ethernet Optic Rotary Joint (FORJ) and subsequently replaced with a wireless system. A new data acquisition module (DAS) was designed and constructed with 7 data channels per module, including influent level monitoring, pressure/load and temperature. A wireless hub was fixed on the centrifuge beam for data transfer from the acquisition modules to a wireless modem outside the centrifuge. Low voltage power to the DAS is transferred to the centrifuge beam via slip rings described by Broadbent (2011).

Each permeameter assembly includes a custom designed reservoir insert (see Fig. S4a and b) and employs a pair of custom designed carbon fibre rod electrical conductivity (EC) electrodes to detect the influent reservoir head to an accuracy of $0.1 \mathrm{~mm}$. The head of influent on the core is typically set to maintain a constant head of influent 20 to $100 \mathrm{~mm}$ above the core sample by selection of electrodes of specific length and is therefore maintained at a constant head during $K$ testing. The electrodes protrude through a pluviator cap into the 
1 influent reservoir, and when the reservoir is depleted a decrease in EC is detected and 2 transmitted back to the PC. The corresponding peristaltic pump is then switched on to automatically pump fluid back into the reservoir. Carbon fibre rod (1 mm diameter) was selected as the electrode material due to its high tensile strength, low mass, high electrical conductivity and its resistance to corrosion.

6 The permeameter is also equipped with effluent reservoir capacity which is connected to the sample via a drainage plate. In order to allow homogenous flow of fluid from the sample surface into the effluent reservoir the drainage plate is lined with one $1 \mathrm{~mm}$ thick A14 Bidim geofabric filter (110 micron, and permeability of $33 \mathrm{~m} \mathrm{~s}^{-1}$; Geofabrics, 2009) and one Whatman 5 qualitative filter paper. The hydraulic conductivity of the drainage plate through a drainage hole of $2 \mathrm{~mm}$ diameter was independently measured to ensure there was no impedance to free drainage. The average permeability $>10$ tests of the drainage plate was $\sim 10^{-}$ ${ }^{5} \mathrm{~m} \mathrm{~s}^{-1}$ (unpublished data), which is typically a factor of 1,000 higher than low permeability core samples.

Effluent is extracted via a syringe or peristaltic pump through a ' $U$ ' shaped tube that connects to the base of the effluent reservoir (Figure S3b). The concave dish base of the effluent reservoir has a volume of $\sim 30 \mathrm{~mL}$. This system, designed by UNSW specifically for these studies, enables samples to be extracted without the need for the permeameters to be taken off the beam, thereby alleviating safety risks in lifting heavy permeameters, and reduces the stop time required for a sampling event during centrifuge flight to less than 5 minutes.

An air vent, located at the top of the reservoir near the lower end of the drainage plate, connects the reservoir to the outside of the permeameter, thereby maintaining a zero pressure outflow boundary. The free drainage boundary condition is different from other centrifuge flow setups and is important for subsequent interpretation of flow processes during.

S4 Limits and uncertainties of centrifuge permeameter testing

$K$ values measured in this study are within the range of applicability of Darcy's Law for laminar flow at accelerated gravity. Flow of fluid through porous media at accelerated gravity was found by Nimmo et al. (1987) to follow Darcy's law for accelerations below 1,600g. The low end of $K$ values that have been measured for geological specimens in the laboratory is $10^{-}$ 
1 flow equilibrium is achieved in a time of hours and days, and in situ stresses can be applied to 2 drill core from approximately $<100 \mathrm{~m}$ depth or a total stress of approximately $1 \mathrm{MPa}$ in the 3 Broadbent CP system (without weighting discs).

4 Hydraulic conductivity data from centrifuge permeameter experiments include a component 5 of measurement error. The quantified components of the measurement error are: limit of reading for time $\pm 0.5 \mathrm{~s}$; limit of reading for permeameter (total mass) balance $\pm 0.5 \mathrm{~g}$; limit of reading for high precision (outflow mass) balance $\pm 0.1 \mathrm{~g}$; limit of reading for influent control burette $\pm 0.1 \mathrm{~mL}$; accuracy of automatic influent control system $\pm 0.1 \mathrm{~mL}$; accuracy of influent fluid level monitoring system $\pm 0.2 \mathrm{~mm}$; fluid held by surface tension in effluent reservoir and on reservoir base plate $< \pm 1.0 \mathrm{~mL}$; evaporation from permeameter chambers $<$ $0.3 \mathrm{~mm} / \mathrm{d}\left(<2.2 \mathrm{~mL} \mathrm{day}^{-1}\right.$ at $\left.875 R P M\right)$.

Sidewall leakage between the core-sample and wall of the permeameter, and any resin that is required to set the core sample for testing has been quantified and is below the hydraulic conductivity detection limit. The current detection limit of the centrifuge permeameter ranges from $3 \times 10^{-11}$ to $1 \times 10^{-12} \mathrm{~ms}^{-1}$. For the semi-consolidated clay core the detection limit, based on low flow measurement was $1 \times 10^{-12} \mathrm{~ms}^{-1}$. For the experimental procedure followed for this study the above volumetric errors translate to an uncertainty in the measurement of $K$ that is typically better than $\pm 15 \%$.

In addition to sidewall leakage, preferential flow can occur through fractures, i.e. features within the core that are either natural or introduced. However, uncertainty due to preferential flow is not a major uncertainty in the centrifuge permeameter because preferential flow is amplified and readily identified. Flow volumes 10 to 80 times greater occur at $10 \mathrm{~g}$ to $80 \mathrm{~g}$ applied in this study, meaning core seal or fracture failures are readily identified from anomalous flow rates and effluent volumes.

Another possible uncertainty with centrifuge permeameter testing is the consolidation and saturation status of core that may affect permeability results. Underestimation of in situ permeability can be attributed to core that is not fully saturated, or to applied stresses that cause consolidation of the core. A bias to high permeability results could occur where the core matrix is unloaded and tested at stresses lower than in situ stresses. 
$1 \quad$ S5 Moisture data from cores, measured on the drill site.

\begin{tabular}{|c|c|c|c|c|c|}
\hline \multicolumn{2}{|l|}{ BF site } & \multicolumn{2}{|l|}{ NR site } & \multicolumn{2}{|l|}{ CL site } \\
\hline $\begin{array}{l}\text { Depth } \\
\text { (m BG) }\end{array}$ & $\begin{array}{c}\text { Moisture } \\
\text { (\% wt.) }\end{array}$ & $\begin{array}{c}\text { Depth } \\
\text { (m BG) }\end{array}$ & $\begin{array}{l}\text { Moisture } \\
\text { (\% wt.) }\end{array}$ & $\begin{array}{c}\text { Depth } \\
\text { (m BG) }\end{array}$ & $\begin{array}{c}\text { Moisture } \\
\text { (\% wt.) }\end{array}$ \\
\hline $0-1.5$ & 23.5 & $0-1.5$ & 26.1 & $1.32-1.38$ & 48.9 \\
\hline $1.5-3.0$ & 24.6 & $1.5-3$ & 27.3 & $2.48-2.88$ & 56.9 \\
\hline $3-4.5$ & 23.4 & $3-4.5$ & 38.1 & $4.33-4.38$ & 42.6 \\
\hline $4.5-6$ & 22.2 & $4.5-6.0$ & 31.7 & $5.83-5.88$ & 35.8 \\
\hline $6.0-7.5$ & 21.2 & $6-6.5$ & 24.0 & 7.33-7.38 & 32.3 \\
\hline $7.5-9.0$ & 25.9 & 7.5-8.65 & 25.7 & $10.33-10.38$ & 40.9 \\
\hline $9-10.5$ & 20.5 & $8.65-10.35$ & 28.6 & 11.83-11.88 & 41.1 \\
\hline $10.5-12$ & 25.0 & $8.65-10.35$ & 27.4 & 13.33-13.38 & 30.2 \\
\hline $12-13.5$ & 27.5 & $10.35-12$ & 26.3 & $14.83-14.88$ & 49.7 \\
\hline $13.5-15$ & 24.1 & $12-13.5$ & 20.9 & $16.30-16.50$ & 48.4 \\
\hline $15-16.5$ & 35.9 & $13.5-15$ & 29.5 & 17.38-17.88 & 44.8 \\
\hline $16.5-18$ & 28.9 & $15-16.5$ & 20.5 & 19.33-19.38 & 48.6 \\
\hline $18-19.5$ & 21.4 & $16.5-18$ & 37.6 & $20.83-20.88$ & 45.2 \\
\hline $19.5-21$ & 26.5 & $18-19.5$ & 26.0 & 22.33-22.38 & 43.5 \\
\hline $21-22.5$ & 18.6 & $19.5-21$ & 23.5 & 23.83-23.88 & 53.1 \\
\hline $22.5-24$ & 27.8 & $21-22.5$ & 24.8 & 26.83-26.88 & 38.2 \\
\hline $24-25.5$ & 23.3 & $22.5-24$ & 25.3 & 28.33-28.38 & 33.9 \\
\hline $26.45-27.3$ & 27.3 & $24-25.5$ & 26.1 & 29.83-29.88 & 34.6 \\
\hline $27.3-28.8$ & 25.0 & $25.5-27$ & 25.8 & 31.33-31.38 & 25.7 \\
\hline 28.8-30.3 & 21.9 & $27-28.5$ & 27.1 & & \\
\hline $30.3-31.8$ & 23.9 & $28.5-30$ & 27.5 & & \\
\hline 31.8-33.3 & 25.4 & $30-31.5$ & 28.3 & & \\
\hline $34.68-34.78$ & 20.4 & $31.5-33$ & 29.2 & & \\
\hline 33.3-34.8 & 21.7 & $33-34.5$ & 28.9 & & \\
\hline $34.8-35.4$ & 17.5 & $34.5-36$ & 27.1 & & \\
\hline
\end{tabular}




$\begin{array}{llll}35.4-36.3 & 16.5 & 36-37.5 & 26.6 \\ 36.3-37.8 & 21.5 & 37.5-39 & 28.0 \\ 37.8-39.3 & 20.6 & 39-40.5 & 28.6 \\ 39.3-40.5 & 23.1 & 40.5-42 & 25.9\end{array}$

$\begin{array}{llll}\text { Average } & 23.6 & & \\ \end{array}$

Average $\quad 41.8$

$1 \mathrm{~m}$ BG is metres below ground, \% wt. is percent weight

\section{References}

3 Broadbent: Operating Manual for Modular Geotechnical Centrifuge with GT2/0.65

4 Permeameter And GT6/0.75 Beam Environments, Broadbent and Sons Ltd., Huddersfield,

$5 \quad$ UK, 2011.

6 Conca, J.L., and Wright, J.: The UFA method for rapid, direct measurements of unsaturated

7 transport properties in soil, sediment and rock, Aust. J. Soil Res. 36, 1-25, 1998.

8 Geofabrics: Bidim ${ }^{\circledR}$ Technical data sheet - nonwoven polyester geotextile. M018 0209.

9 Geofabrics Australasia Pty Ltd, 2009.

10 McCartney, J.S.: Determination of the Hydraulic Characteristics of Unsaturated Soils using a

11 Centrifuge Permeameter. PhD Thesis, The University of Texas at Austin, Faculty of the

12 Graduate School, 2007.

13 Nakajima H., and Stadler, A.T.: Centrifuge modeling of one-step outflow tests for unsaturated 14 parameter estimations. Hydrol. Earth Syst. Sci., 10, 715-729, 2006.

15 Nimmo, J.R., and K.A. Mello, K.A.: Centrifugal techniques for measuring saturated hydraulic 16 conductivity. Water Resour. Res. 27 (6), 1263-1269, 1991.

17 Nimmo, J.R., Rubin, J., and Hammermeister, D.P.: Unsaturated flow in a centrifugal field:

18 measurement of hydraulic conductivity and testing of Darcy’s Law. Water Resour. Res.,

19 23(1):124-134, 1987.

20 Timms, W.A. and Hendry, M.J.:. Application of centrifuge modelling to assess long term 21 brine migration in thick clay till, Saskatchewan, Canada., Australian Institute of Mining and

22 Metallurgy Conference “Water in Mining”, Brisbane, October 13-15, pp. 363-372, 2003.

Timms, W., Whelan, M., Acworth, I., McGeeney, D., Bouzalakos, S., Crane, R., McCartney, 24 J. and Hartland, A.: A novel centrifuge permeameter to characterize flow through low 25 permeability strata. In proceedings of International Congress on Physical Modelling in 26 Geotechnics (ICPMG), Perth, Balkema, 14-17 January, 2014. 
1 Zornberg, J.G., and McCartney, J.S.: Centrifuge Permeameter for Unsaturated Soils. I:

2 Theoretical Basis and Experimental Developments. J. Geotechnical and Geoenvironmental 3 Engineering, 136, 8, 1051-1063, 2010. 
1 Fig. S1. Schematic diagram of the NCGRT geotechnical centrifuge and permeameter module in 2 cross-section (Broadbent, 2011).

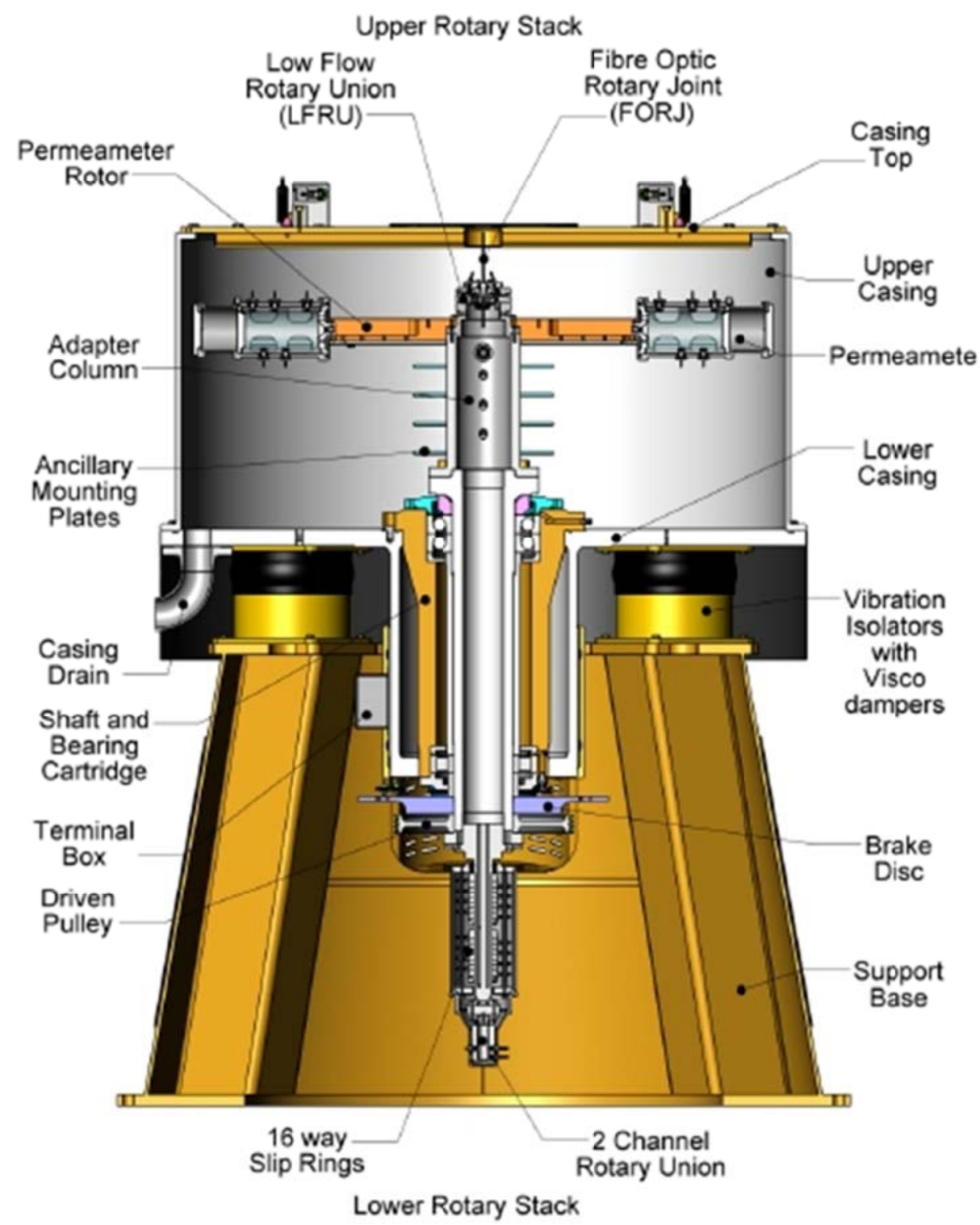


$1 \quad$ Fig. S2. Fluid head pressure (hydrostatic), total stress and effective stress (difference between total 2 stress and effective stress) at $40 \mathrm{~g}$ in this study.

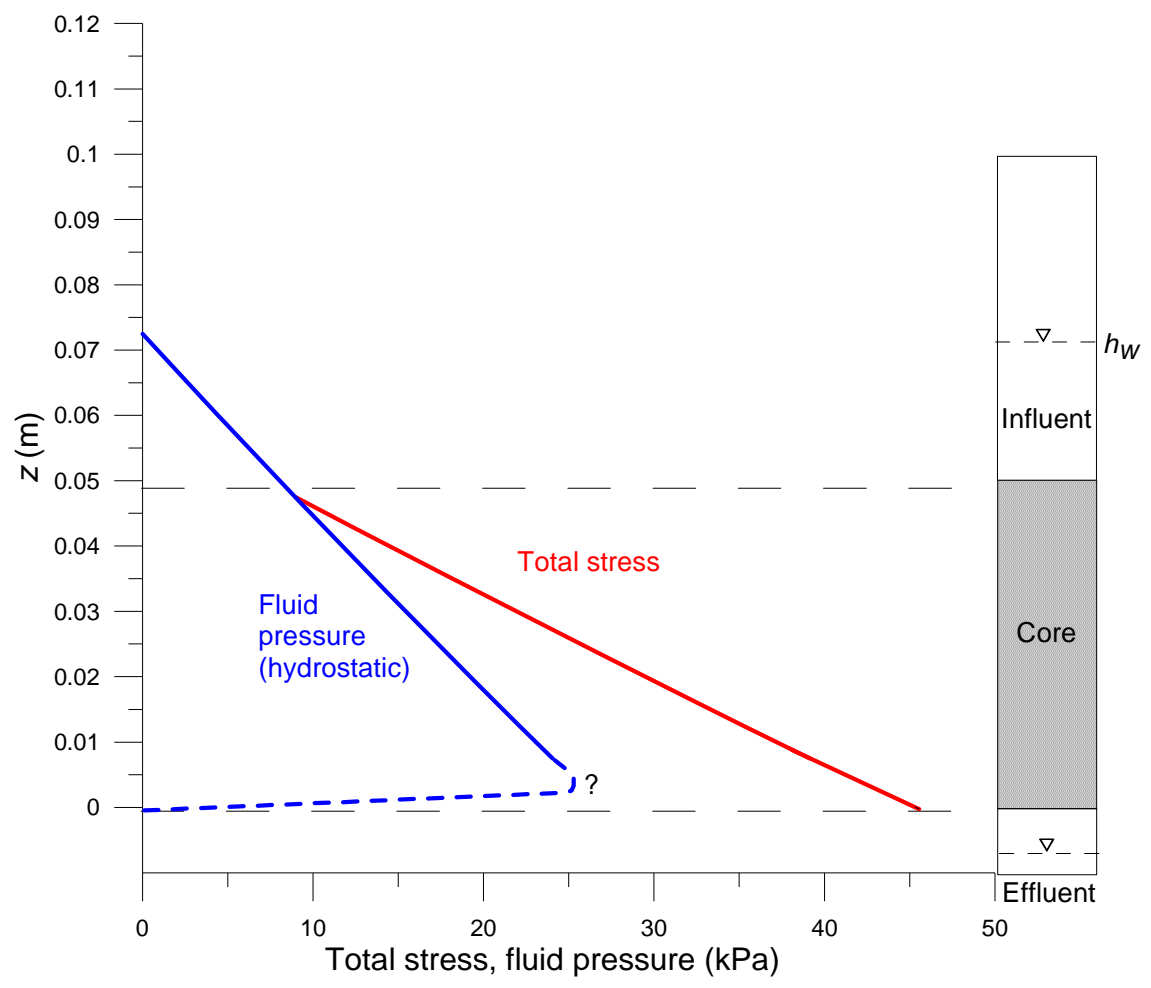


1 Fig. S3. (a) Conceptual relationship between hydrostatic fluid pressure, centrifuge inertial (elevation) 2 head for a core in a centrifuge permeameter as a function of $\mathrm{z}$ (Figure 1). The direction of centrifugal 3 acceleration and fluid flow is indicated by the arrow $\mathrm{Ng}$. Alternative drainage boundary condition 4 (DBC) and pressure boundary condition (PBC) are indicated at the base of the core sample. (b) Fluid 5 head gradient at $1 g$ and centrifuge inertial head gradients for the UFA and Broadbent (CP module) 6 centrifuges at $40 \mathrm{~g}$

(a)

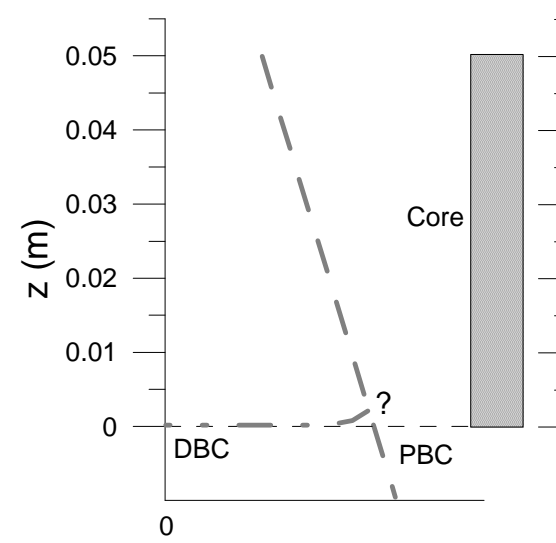

Fluid pressure (hydrostatic) (b)

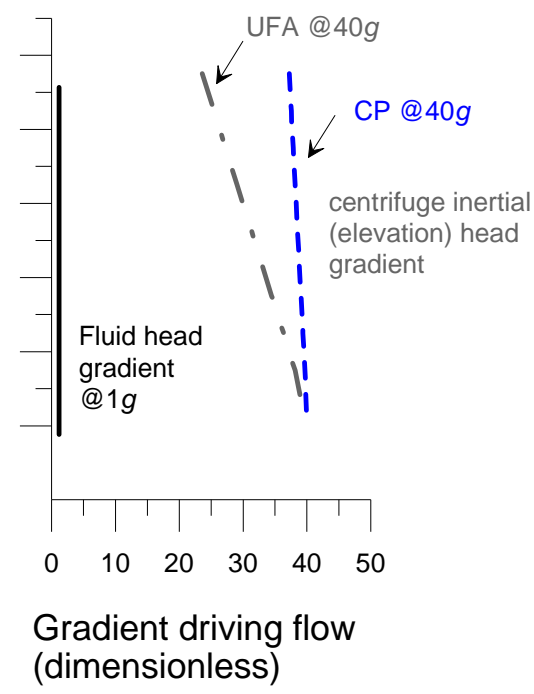


1 Fig. S4. Cross section of the (a) centrifuge permeameter and beam showing new reservoir and 2 reference points and (b) detail of new reservoir liner with suction extraction port.

3

$4 \quad$ (a)

5

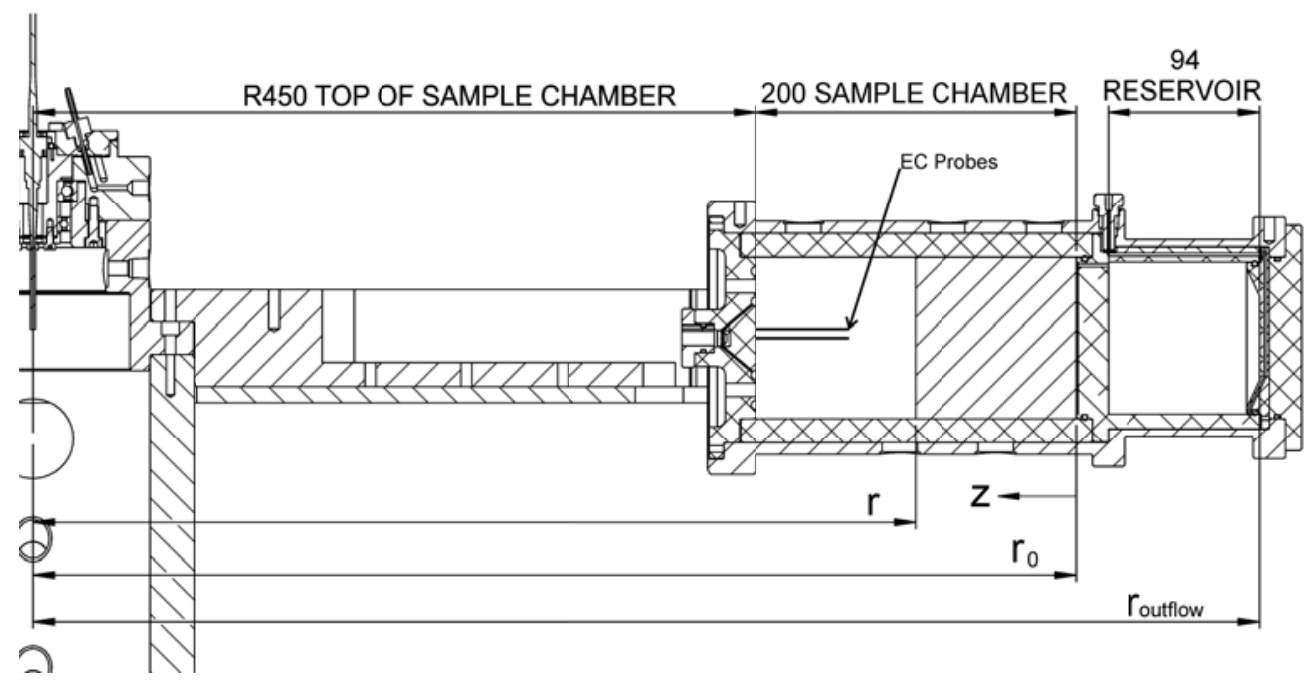

6

$7 \quad$ (b)

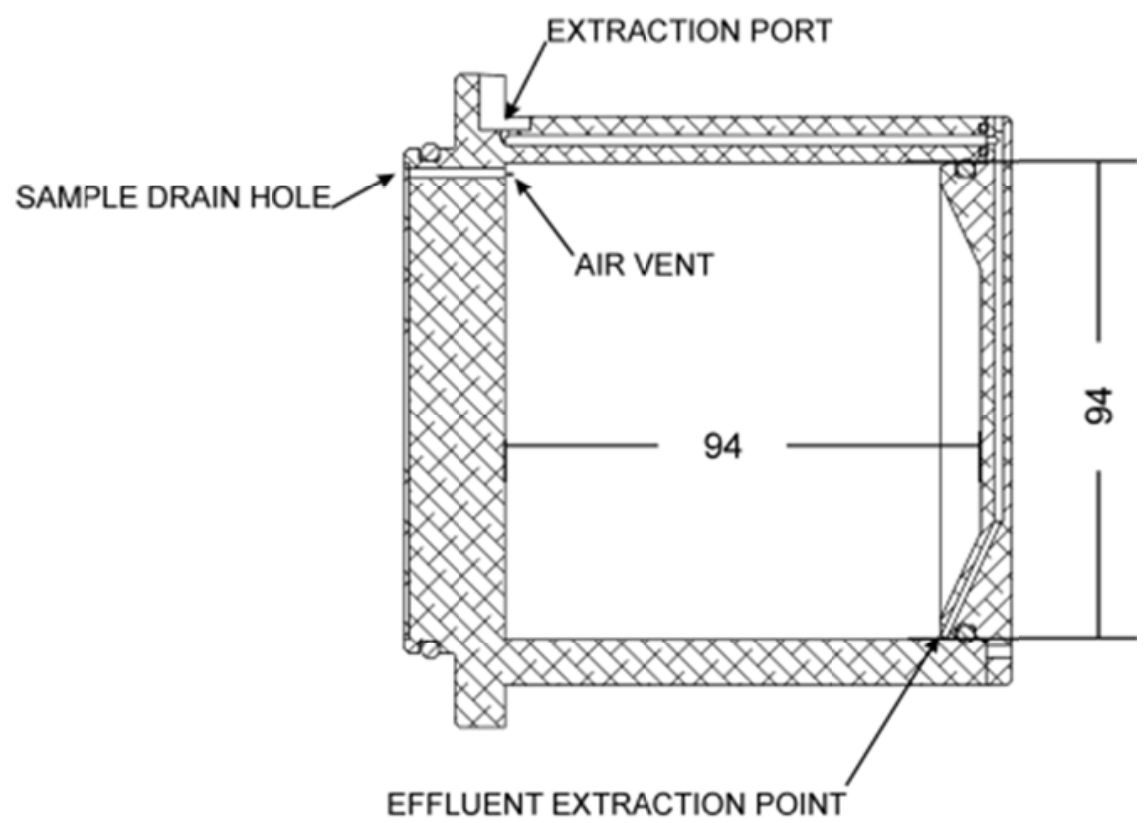

8 